Acta Crystallographica Section B

Structural

Science

ISSN 0108-7681

\title{
Morphotropism: link between the isostructurality, polymorphism and (stereo)isomerism of organic crystals
}

An ongoing analysis of the supramolecular self-assembly of disubstituted cycloalkanes has led to the discovery of seven packing patterns built up from hydrogen-bonded homo- and heterochiral chains of racemic molecules, associated in either antiparallel or parallel arrays [Kálmán et al. (2001). Acta Cryst. B57, 539-550]. Two further patterns have been revealed in the close packing of analogous alicyclic $\beta$-amino acids [Fábián et al. (2005). Cryst. Growth Des. 5, 773-782]. Since each pattern is represented by at least one crystal structure, the chemical similarity and crystallographic forms of these crystals have facilitated the recognition that these patterns differ by one or two rotation(s) of the common motifs (e.g. dimers, tetramers, helices etc.), or the whole pattern may rotate through $180^{\circ}$ in an oblique unit cell. Such non-crystallographic - with the exception of polymorphism - virtual rotations as a whole may be denoted by the expression morphotropism. According to Kitaigorodskii [(1961), Organic Chemical Crystallography, pp. 222-231. New York: Consultants Bureau], morphotropism is an attempt to keep the packing coefficient above 0.6 whenever there are alternative possibilities for the structures of closely related molecules. It has been found that crystals of stereoisomers are also frequently related by such virtual rotations. Similarly, non-crystallographic rotations effect bridges between homostructural crystals [Kálmán et al. (1993b). Acta Cryst. B49, 1039-1049] and occasionally hallmark the polymorphism of organic compounds [Kálmán et al. (2003) J. Am. Chem. Soc. 125, 34-35]. In polymorphs, however, such rotations really transform one molecule into another in order to achieve a better packing mediated by solvents, temperature etc.

\section{Introduction}

In his seminal book Organic Chemical Crystallography, ${ }^{\mathbf{1}}$ Kitaigorodskii (1961) dealt with, among other topics, the isomorphism of organic molecules. His examples were mainly halo compounds with molecular similarities, which he considered to be sufficient to give rise to isomorphous crystals. From this conclusion, he jumped directly to the suggestion that 'it is therefore of some interest to determine the intermolecular spacing in non-isomorphous crystals of compounds with similar molecules. We explain the morphotropic step as due to the impossibility of maintaining a sufficiently high packing coefficient for isomorphous substitution'. He referred to tetra- $p$-ethoxyphenyltin $\left\{\left[\mathrm{Sn}\left(\mathrm{C}_{2} \mathrm{H}_{5} \mathrm{OC}_{6} \mathrm{H}_{4}\right)_{4}\right]\right\}$, which, unlike

\footnotetext{
1 The original Russian issue was published by the Publishing House of the

Academy of Sciences of the USSR in Moscow in 1955.
}

Received 4 March 2005 Accepted 20 July 2005
(C) 2005 International Union of Crystallography Printed in Great Britain - all rights reserved 
Table 1

A list and labels of compounds (depicted in Fig. 1) discussed in the text.

\begin{tabular}{|c|c|}
\hline$(\mathrm{I} a),(\mathrm{I} b)$ & cis- and trans-2-Hydroxycyclooctanecarboxylic acids \\
\hline (II $a)$ & $\begin{array}{l}\left(1 R^{*}, 2 S^{*}, 4 R^{*}\right)-4 \text {-tert-Butyl-2-hydroxycyclopentanecarb- } \\
\quad \text { oxylic acid }\end{array}$ \\
\hline (II b) & $\begin{array}{l}\left(1 R^{*}, 2 S^{*}, 4 S^{*}\right) \text {-4-tert-Butyl-2-hydroxycyclopentanecarb- } \\
\quad \text { oxylic acid }\end{array}$ \\
\hline (II c) & $\begin{array}{l}\left(1 R^{*}, 2 S^{*}, 5 R^{*}\right) \text {-5-tert-Butyl-2-hydroxycyclopentanecarb- } \\
\quad \text { oxylic acid }\end{array}$ \\
\hline (III $b)$ & trans-2-Hydroxycyclopentanecarboxylic acid \\
\hline$(\mathrm{IV} a)$ & droxycyclohexanecarboxylic acid \\
\hline$(\mathrm{V} a),(\mathrm{V} b)$ & cis- and trans-2-Hydroxycycloheptanecarboxylic acids \\
\hline$(\mathrm{V} b)^{(p)},(\mathrm{V} b)^{(a)}$ & Homostructural dimorphs of $(\mathrm{V} b)$ \\
\hline$(\mathrm{VI} b)$ & $\begin{array}{l}\left(1 R^{*}, 2 R^{*}, 4 S^{*}\right) \text {-4-tert-Butyl-2-hydroxycyclopentanecarb- } \\
\quad \text { oxamide }\end{array}$ \\
\hline$(\mathrm{VII} a),(\mathrm{VII} b)$ & cis- and trans-2-Hydroxycyclopentanecarboxamides \\
\hline$(\mathrm{VIII} b)$ & trans-2-Hydroxycycloheptanecarboxamide \\
\hline$(\mathrm{IX} \alpha$ & olymorphs of glycine \\
\hline$(\mathrm{X} \alpha)$, & us polymorphs of nitrofurantoin \\
\hline$(\mathrm{XI} \alpha),(\mathrm{XI} \beta)$ & $\begin{array}{l}\text { Isostructural dimorphs of trans-13-azabicyclo[10.2.0]tetra- } \\
\text { decan-13-one }\end{array}$ \\
\hline (XII $a)$ & cis-2-Aminocyclopentanecarboxylic acid \\
\hline$(\mathrm{XIII} a),(\mathrm{XIII} b)$ & cis- and trans-2-Aminocyclohexanecarboxylic acids \\
\hline$(\mathrm{XIV} a)$ & \\
\hline$(\mathrm{XV} a)$ & cis-2-Aminocyclooctanecarboxylic acid \\
\hline$(\mathrm{XVI} a),(\mathrm{XVI} b)$ & cis- and trans-2-Aminocyclohex-4-enecarboxylic acids \\
\hline
\end{tabular}

the tetragonal crystals of the closely related $\left[\mathrm{Sn}\left(\mathrm{C}_{6} \mathrm{H}_{5}\right)_{4}\right]$, $\left[\mathrm{Sn}\left(\mathrm{CH}_{3} \mathrm{C}_{6} \mathrm{H}_{4}\right)_{4}\right]$ and $\left[\mathrm{Sn}\left(\mathrm{CH}_{3} \mathrm{OC}_{6} \mathrm{H}_{4}\right)_{4}\right]$, is monoclinic. He stated that the observed rearrangement maintains the packing density at $c a 0.67$. Otherwise, it would have dropped below 0.6. The essence of morphotropism remained unexplored, however.

More than 30 years later, we wrote a paper $^{2}$ on the isostructuralism of organic molecules in terms of Kitaigorodskii's early perception (Kálmán et al., 1993a). Among the examples was on a packing rearrangement which was observed twice in a series of organometallic compounds related by isostructurality. While $\mathrm{Me}_{3} \mathrm{Si}_{-} \mathrm{SiPh}_{3}$ (Párkányi \& Henge, 1982) and its analogs $\mathrm{Me}_{3} \mathrm{Si}-\mathrm{GePh}_{3}$ (Párkányi et al., 1986) and $\mathrm{Me}_{3} \mathrm{Ge}-\mathrm{SiPh}_{3}$ (Pannell et al., 1990) form trigonal crystals (common space group, $P \overline{3}$ ), the isomeric $\mathrm{Me}_{3} \mathrm{Ge}-$ $\mathrm{SnPh}_{3}$ and $\mathrm{Me}_{3} \mathrm{Sn}-\mathrm{GePh}_{3}$ are pseudohexagonal with the orthorhombic space group Pna2 ${ }_{1}$ (Pannell et al., 1992). In the former case, the $\mathrm{Me}_{3} E-E^{\prime} \mathrm{Ph}_{3}$ dumbbells related by a center of symmetry are antiparallel, whereas in the orthorhombic pair of structures they are stacked in a parallel array. Continuing these investigations, we found that the crystals of $\mathrm{Me}_{3} \mathrm{Ge}-$ $\mathrm{GePh}_{3}$ (Párkányi et al., 1994), $\mathrm{Me}_{3} \mathrm{Sn}-\mathrm{SnPh}_{3}$ (Párkányi et al., 1996) and some others, such as $\mathrm{Me}_{3} \mathrm{~Pb}_{-} \mathrm{SnPh}_{3}$ and $\mathrm{Me}_{3} \mathrm{~Pb}-$ $\mathrm{PbPh}_{3}$ (Preut \& Huber, 1976), are again trigonal with the space group $P \overline{3}$. A $180^{\circ}$ rotation of the $R_{3} \mathrm{Ge}-\mathrm{Sn} R_{3}^{\prime}$ dumbbells, perpendicular to the respective $E-E^{\prime}$ bond, was attributed (Kálmán \& Párkányi, 1997) to the $0.19 \AA$ difference in the covalent radii of Ge and $\mathrm{Sn}$ with respect to those of 0.11 and $0.06 \AA$ observed between the $\mathrm{Ge}-\mathrm{Si}$ and $\mathrm{Pb}-\mathrm{Sn}$ pairs, respectively. In accordance with Kitaigorodskii's perception, we claimed that 'in these pseudohexagonal unit cells, the bumps of the molecules stacked with similar orientation along

\footnotetext{
2 This was a contribution to the A. I. Kitaigorodskii Memorial Issue on Molecular Crystal Chemistry (Hargittai \& Kálmán, 1993).
}

the polar $c$-axis fit perfectly into the hollows of the adjacent columns generated by glide planes, thereby forming new efficient close packing'.

Although the $P \overline{3} \rightarrow P n a 2_{1}$ rearrangement is a $180^{\circ}$ rotation of every second dumbbell in the unit cell, we did not feel (Kálmán \& Párkányi, 1997) these examples to be sufficient for morphotropism to be regarded as a rotation of motif(s) in general, as suggested by the mirror translation of the Greek words 'morphos' (shape) and 'trópos' (turn) or 'tropé' (turning). Neither the symmetrical spirosulfurane (Kálmán et al. , 1973) nor the analogous spiroselenourane (Dahlén, 1974), with parallel (space group $F d d 2$ ) and antiparallel (space group $C 2 / c$ ) molecules sitting on twofold axes, compelled us to recognize the importance of non-crystallographic rotations in crystal chemistry. Now, 50 years after Kitaigorodskii's publication, the present paper aims to explore the essence of morphotropism. Several forms of morphotropism between isostructural crystals, polymorphs and stereoisomeric pairs are presented, recognized in a survey of the crystal structures of 2hydroxycycloalkanecarboxylic acids, analogous carboxamides, alicyclic $\beta$-amino acids and their $\beta$-lactam derivatives determined in our laboratory. These molecules, together with a few examples of morphotropism found by chance in the literature, are listed in Table 1 and depicted in Fig. 1.

First, we recognized that the racemic crystals of these compounds are built up from hydrogen-bonded homo- or heterochiral chains in either antiparallel or parallel arrays (Kálmán et al., 2001, 2002a). They form seven packing patterns, which can be transformed into each other directly or indirectly (Kálmán et al., 2002b). Several pairs of crystals with different degrees of isostructurality were discerned (Kálmán et al., 2001, 2002a,b). Novel forms of polymorphism and isostructurality were then observed, which could be attributed to non-crystallographic rotations between common motifs (Kálmán et al., 2003, 2004). Finally, a study of the isostructurality of four cis-alicyclic $\beta$-amino acids, tested against ring deformation (the cyclohexane ring was replaced by the cyclohexene ring) and stereoisomerism (Fábián et al., 2005), revealed two different forms of close packing, differing in the non-crystallographic rotations of a common motif. Bearing in mind the antiparallel versus parallel fits of the $\mathrm{Me}_{3} E-E^{\prime} \mathrm{Ph}_{3}$ dumbbells (Kálmán \& Párkányi, 1997) mentioned above, the novel examples must be regarded as morphotropes. This led belatedly (by 50 years) to the elucidation of the morphotropism exhibited by isomers, isostructures and polymorphs.

\section{The forms of morphotropism}

\subsection{Rotation of dimers}

Four of the seven patterns built up from either heterochiral or homochiral chains of racemic molecules in an antiparallel array are characterized by dimers (Kálmán et al., 2002a), described by the graph-set notation $R_{2}^{2}(12)$ (Etter, 1990; Bernstein et al., 1995). They are distinguished by their acceptor groups (either $\mathrm{OC}$ or $\mathrm{OH}$ ) which can be interconverted by a simultaneous $180^{\circ}$ rotation of the $\mathrm{COOH}$ and 


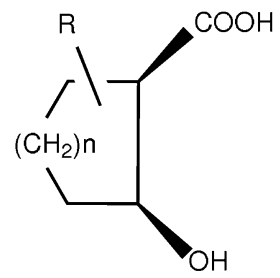

R: $4 R^{\star} 4 S^{\star} 5 R^{\star}$ tBu lla Ilb Ilc
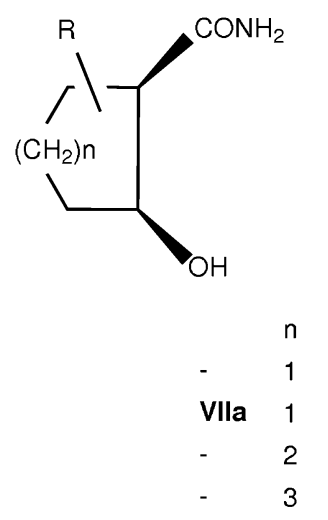

$\mathbf{I X}(\alpha, \beta)$
$\mathrm{H}_{2} \mathrm{~N}-\mathrm{CH}_{2}-\mathrm{COOH}$

$\mathbf{X I}(\alpha, \beta)$<smiles>CC1CCC2NC(=O)C2CC1</smiles>

XIla-XVa $(n=1,2,3,4)$

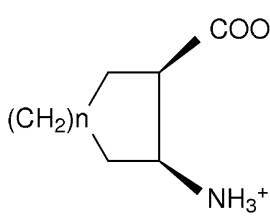

XVla<smiles>[NH3+][C@@H]1CC=CC[C@H]1C(=O)[O-]</smiles>
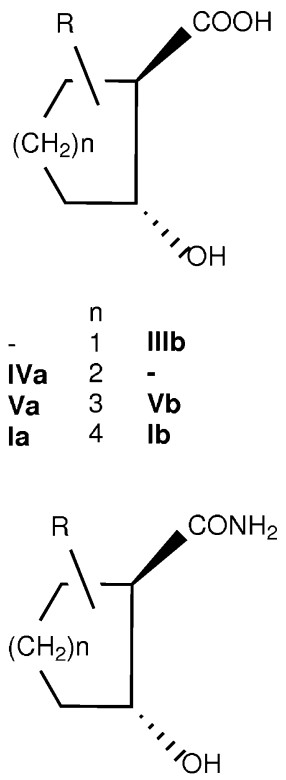

$$
\begin{array}{ll}
R & \\
4 S^{*}-^{-} B u & \text { VIb } \\
H & \text { VIIb } \\
H & - \\
H & \text { VIIIlb }
\end{array}
$$

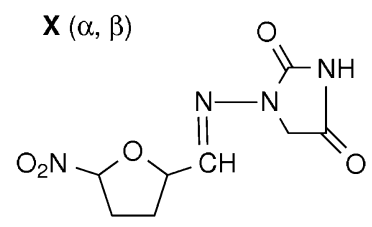

XIIIb<smiles>[NH3+][C@@H]1CCCCC1C(=O)[O-]</smiles>

XVIb<smiles>[NH3+][C@@H]1CC=CC[C@H]1C(=O)[O-]</smiles>

Figure 1

Chemical line drawings of the molecules labeled from (I $a)$ to (XVI $b$ ).

$\mathrm{OH}$ moieties. Separately, these dimer motifs may exist in lateral associations held together by $R_{4}^{4}(12)$ tetramers, while their linear association is the same, since either type generates the other dimer. This linear array, demonstrated by trans-2hydroxycyclooctanecarboxylic acid $(\mathrm{I} b),{ }^{\mathbf{3}}$ is therefore unique

${ }^{3}$ The cis and trans isomers are distinguished by bold $a$ and $b$.

(Kálmán et al., 2002b). It is the basic pattern (1) from which (Fig. 2) the others can be deduced by non-crystallographic rotations of the $\mathrm{OC}$ or $\mathrm{OH}$ dimers.

To visualize such rotations the symbolic (topological) presentation of the packing patterns that we have introduced (Kálmán et al., 2002a,b) is convenient. To simplify the homologous 1,2-disubstituted alicyclic (cyclopentane $\rightarrow$ cyclooctane) monomers (Fig. 3a), the saturated rings are omitted, while the functional groups are depicted by graphical symbols. A straight line represents an $\mathrm{OH}$ group, a circle a $\mathrm{CO}$ group and a triangle (in carboxamides) an $\mathrm{NH}_{2}$ group (Fig. $3 b$ ). To distinguish between the $\mathrm{C} 1-R$ and $\mathrm{C} 1-S$ enantiomers the symbols are converted into black or white triangles (Fig. $3 c$ ). The hydrogen bonding in the heterochiral $\mathrm{OC}$ and $\mathrm{OH}$ dimers is denoted by dotted lines (Fig. $3 d$ ). In the topological descriptions, the $\mathrm{OC}$ and $\mathrm{OH}$ dimers simply rotate around their center of symmetry through either 90 or $180^{\circ}$. We apply these symbols in the analysis of pattern 1 depicted in Fig. 4(a), which shows the two parallel molecular ribbons in which the $\mathrm{OC}$ and $\mathrm{OH}$ dimers alternate. These dimers are taken to rotate through 90 or $180^{\circ}$ as follows:

(i) A rotation of every second dimer (either $\mathrm{OC}$ or $\mathrm{OH}$ ) through $90^{\circ}$ results in their lateral association 2 with the alternatives $\mathbf{2} \boldsymbol{a}$ and $\mathbf{2 b}$ held together by $R_{4}^{4}(12)$ tetramers of $C_{\mathrm{i}}$ symmetry (Fig. 4b). The sub-patterns $2 \boldsymbol{a}(\mathrm{OC})$ and $\boldsymbol{2} \boldsymbol{b}(\mathrm{OH})$ retain the triclinic space group $P \overline{1}$ from $\mathbf{1}$.

(ii) The motifs in sub-patterns $\mathbf{2} \boldsymbol{a}$ and $\mathbf{2} \boldsymbol{b}$ are stacked in a parallel orientation, which, similarly to the $R_{3} E-E^{\prime} R_{3}^{\prime}$ dumbbells (Kálmán \& Párkányi, 1997), can be rearranged in an antiparallel mode by a $180^{\circ}$ rotation of every second dimer in unison. In the novel sub-patterns $\mathbf{3} \boldsymbol{a}$ and $\mathbf{3} \boldsymbol{b}$ (Fig. $4 c$ ), the symmetry of the $R_{4}^{4}(12)$ tetramers alters from $C_{i}$ to $C_{2}$, while the space group changes from $P \overline{1}$ to $C 2 / c$.

(iii) The rearrangement of sub-patterns $\mathbf{3 a}$ and $\mathbf{3 b}$ is continued if the antiparallel motifs are rotated through $90^{\circ}$ around their main axis in unison. Thus, once again, two linear associations $\mathbf{4 a}$ and $\mathbf{4 b}$ are obtained (Fig. $4 d$ ), in which the heterochiral dimers are separated by homochiral dimers, which in the crystalline state readily polymerize into infinite helices. ${ }^{\mathbf{4}}$ These packing patterns $(\mathbf{4} \boldsymbol{a}$ and $\mathbf{4 b})$ display monoclinic symmetry with the space group $P 2_{1} / c$. The three patterns $\mathbf{2}, \mathbf{3}$ and $\mathbf{4}$ (except for $\mathbf{2 a}$ ) are exemplified by the crystal structures listed in Table 2.

Although the symbolic descriptions of the crystal structures do have advantages and predictive power, they conceal the relevant three-dimensional information, e.g. the planar and folded conformations of the dimers cannot be seen. In addition, it must be remembered that dimers rotate through $90^{\circ}$ around their main axes, ${ }^{\mathbf{5}}$ while their $180^{\circ}$ rotation takes place perpendicularly to their main axes (see Fig. $2 a$ versus $b$ ). Nevertheless, these symbols enable us to describe the morphotropism observed between the crystal structures which are 'non-isomorphous'.

\footnotetext{
${ }^{4}$ To diminish the empty channels in the unit cell, i.e. to increase the closepacking coefficient, the principal factor in Kitaigorodskii's realm.

${ }^{5}$ The main axis is defined by a vector between the remotest $\mathrm{CH}_{2}$ groups of the opposite cycloalkane rings.
} 
Table 2

Packing patterns and their space groups assumed by the investigated disubstituted cycloalkane molecules.

$\leftrightarrow$ : isostructural pairs and groups; $\leftarrow^{2} \rightarrow$ : with alternating (two-dimensional layers); (I), (/): with different orientations in oblique unit cells.

\begin{tabular}{|c|c|c|}
\hline Patterns & Space groups & Molecules \\
\hline 1 & $P \overline{1}$ & $(\mathrm{I} b)$ \\
\hline $2 b$ & $P \overline{1}$ & $(\mathrm{II} b)$ \\
\hline $3 a$ & $C 2 / c$ & $(/)(\mathrm{III} b) \leftrightarrow(\mathrm{IV} a)(60 \%)$ \\
\hline $3 b$ & $C 2 / c(I 2 / c)$ & $(\mathrm{IV} a)(40 \%) \leftrightarrow(\backslash)(\mathrm{V} a)$ \\
\hline $4 a$ & $P 2_{1} / c$ & $(\mathrm{VI} b)$ \\
\hline $4 b$ & $P 2_{1} / c$ & (Ia) \\
\hline 5 & $\mathrm{Pca}_{1}, \mathrm{Pbca}$ & $(\mathrm{VII} b) \leftarrow^{2} \rightarrow(\mathrm{VIII} b)$ \\
\hline 6 & $P 2_{1} / c$ & $(/)(\mathrm{II} a) \leftrightarrow(।)(\mathrm{VII} a)$ \\
\hline 7 & $P 2_{1} / n\left(P n a 2_{1}, P n 2_{1} a\right)$ & $(\mathrm{I} c),\left[(\mathrm{V} b)\left(\left(^{p}\right) \leftarrow^{2} \rightarrow(\mathrm{V} b)\left({ }^{a}\right)\right]\right.$ \\
\hline $8 a$ & $P \underline{1}$ & $(/)(\mathrm{XII} a) \leftrightarrow(\mathrm{XIII} a) \leftrightarrow(\mathrm{XIV} a) \leftrightarrow$ \\
\hline $8 b$ & $P \overline{1}$ & $\leftrightarrow(\backslash)(\mathrm{XV} a)$ \\
\hline $9 a$ & $P 2_{1} / c$ & $(/)(\mathrm{XVI} a) \leftrightarrow$ \\
\hline $9 b$ & $P 2_{1} / c$ & $\leftrightarrow(\backslash)(\mathrm{XIII} b) \leftrightarrow(\mathrm{XVI} b)$ \\
\hline
\end{tabular}

Kitaigorodskii (1961) guessed that the best way to find morphotropism is the study of isostructural crystals surrounded by 'non-isomorphous' relatives. This guess is substantiated by the homologs (III $b),(\mathrm{IV} a)$ and $(\mathrm{V} a)$ (space group $C 2 / c$ ), which are isostructural (Kálmán et al., 2002a), while the fourth member of the series, cis-2-hydroxycyclooctanecarboxylic acid ( $\mathrm{I} a$ ), forms crystals in the space group $P 2_{1} / c$ (Kálmán et al., 2002b). The sub-patterns $\mathbf{3 a}$ and $\mathbf{4 a}$ are related by a dimer rotation through $90^{\circ}$. It is noteworthy that the sub-pattern $\mathbf{4 a}$ and the basic pattern $\mathbf{1}$ are related directly by a rotation of the OC dimers (Fig. $3 d$ ) through $180^{\circ}$
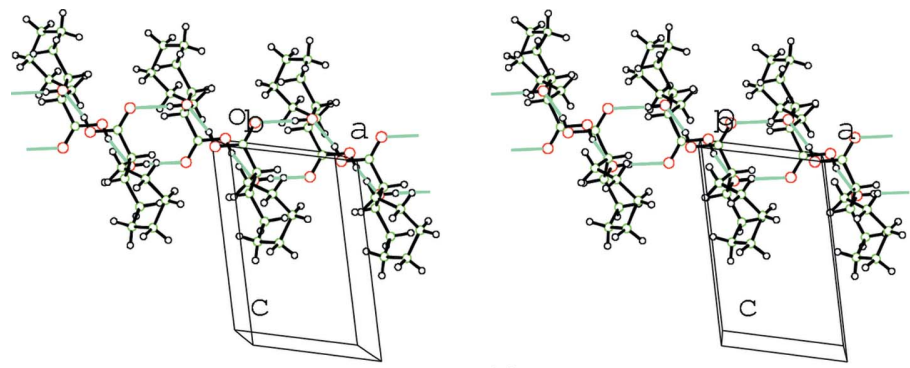

(a)
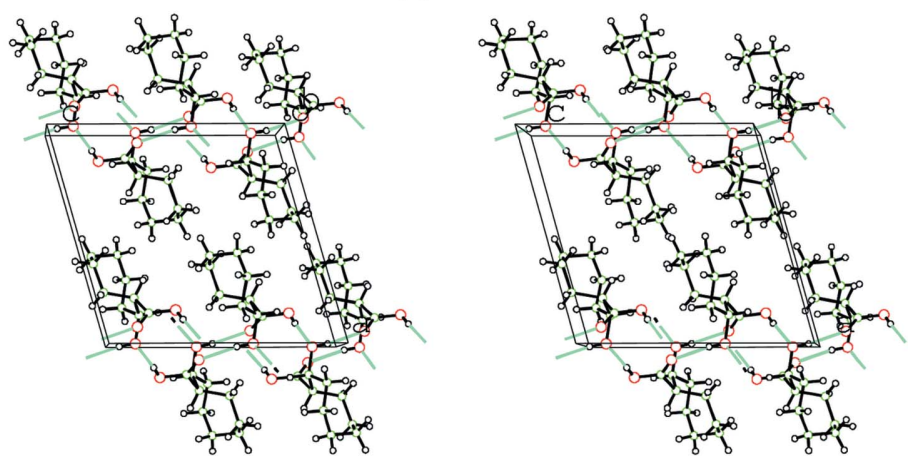

(b)

Figure 2

Stereoviews of the molecular packing of $(\mathrm{I} b)(P \overline{1})$ and $(\mathrm{I} a)\left(P 2_{1} / c\right)$. They are related by the type of rotation from $\mathbf{1} \rightarrow \mathbf{4 b}$. Their common motif is the folded OC dimer located between planar $\mathrm{OH}$ dimers in $(\mathrm{I} b)$ and between helices in $(\mathrm{I} a)$. (Reproduced from Kálmán et al., 2002b.)
(Figs. $4 a$ and $d$ ). In other words, the structures of ( $\mathrm{I} a$ ) and (Ib), differing only in the chirality of the $\mathrm{C} 2$ atom, can be virtually converted into another by a non-crystallographic rotation. Thus, they may be regarded as morphotropes.

\subsection{Rotation of helices}

In order to increase the packing coefficient the homochiral dimers in patterns $\mathbf{4} \boldsymbol{a}$ and $\boldsymbol{4} \boldsymbol{b}$ polymerize into helices, which can be seen if they are shown in two dimensions (Fig. 5). The antiparallel helices with opposite chirality are held together by the retained (either $\mathrm{OC}$ or $\mathrm{OH}$ ) dimer motifs. In $\left(1 R^{*}, 2 R^{*}, 4 S^{*}\right)$-4-tert-butyl-2-hydroxycyclopentanecarboxamide (VIb) (Kálmán et al., 2001), the helices are held together by $\mathrm{OH}$ dimers (Fig. $5 b$ ). In contrast, in the tert-butyl free trans-2-hydroxycyclopentanecarboxamide (VIIb), a $180^{\circ}$ rotation of either of the enantiomorphic (back and white) helices forms a polar crystal with the space group $P c a 2_{1}$. In this pattern (6), the parallel helices are held together by glide planes enclosing heterochiral rings (Fig. $5 c$ ) described by the graph-set notation $R_{4}^{3}(18)$. Of course, the non-crystallographic rotation between the structures (Figs. $5 b$ and $c$ ) of the related $(\mathrm{VI} b)$ and (VII $b)$ molecules is only virtual. However, these virtual rotations shed light upon the packing similarities of closely related compounds.

In an alternative step, the antiparallel helices in pattern $\mathbf{4}$ may also reassemble in a lateral stacking mode (pattern 5) by a $90^{\circ}$ rotation around the twofold screw axes (Fig. 4e), as demonstrated by cis-2-hydroxycyclopentanecarboxamide (VII $a$ ) (Kálmán et al., 2001). In pattern $\mathbf{5}$, the helices are held together by $R_{4}^{4}(12)$ tetramers of $C_{i}$ symmetry. Accordingly, the stereoisomers (VII $a$ ) with monoclinic crystals (space group $P 2_{1} / c$ ) and (VII $b$ ) with orthorhombic crystals (space group $P c a 2_{1}$ ) are morphotropes again. These stereoisomers are related by two consecutive virtual rotations.

\subsection{Rotations of tetramers}

The polar layers (pattern $6 \boldsymbol{b}$ ) in parallel stacking, observed in (VII $b$ ), may also be rearranged into an antiparallel array. A $180^{\circ}$ rotation of every second layer of the tetrameric $R_{4}^{3}(18)$ rings gives rise to antiparallel stacking (Kálmán et al., 2004). The nonisomorphous (Table 3) two dimensional isostructurality of the parallel (space group $P c a 2_{1}$ ) and the antiparallel (space group Pbca) stackings of (VII $b$ ) and the (VIIIb) (trans-2-hydroxycycloheptanecarboxamide) are depicted in Fig. 6 taken from Kálmán et al. (2004).

Pattern 7 is the parallel association of heterochiral chains (Kálmán et al., 2001, 2002a). The molecules, invariably linked by hydrogen bonds, form exclusively heterochiral tetramers described by the graph-set notation $R_{4}^{4}(18)$. These rings are antidromic (see Appendix $A$ ), which generates dipoles. However, the dipoles must cancel out over the whole crystal by antiparallel stacking of either 
Table 3

Crystal data on selected morphotropic pairs (isostructures and polymorphs).

\begin{tabular}{|c|c|c|c|c|c|c|c|c|}
\hline & $a(\AA)$ & $b(\AA)$ & $c(\AA)$ & $\alpha\left(^{\circ}\right)$ & $\beta\left(^{\circ}\right)$ & $\gamma\left({ }^{\circ}\right)$ & $V\left(\AA^{3}\right)$ & Space group \\
\hline$(\mathrm{VII} b)$ & $8.250(2)$ & $8.410(2)$ & 9.879 (2) & 90 & 90 & 90 & $685.4(3)$ & $P 2_{1} c a$ \\
\hline (VIII $b$ ) & $8.248(1)$ & $19.679(3)$ & $10.581(1)$ & 90 & 90 & 90 & $1717.4(4)$ & Pbca \\
\hline$(\mathrm{V} b)\left({ }^{p}\right)$ & $21.184(3)$ & $6.824(1)$ & $5.892(2)$ & 90 & 90 & 90 & $851.7(3)$ & $P n a 2_{1}$ \\
\hline$(\mathrm{V} b)\left({ }^{a}\right)$ & $21.185(2)$ & $6.826(1)$ & $5.889(1)$ & 90 & 90 & 90 & $851.6(2)$ & $P n 2_{1} a$ \\
\hline$(\mathrm{IX} \alpha)$ & $5.0993(3)$ & $11.9416(6)$ & $5.4608(3)$ & 90 & $111.784(2)$ & 90 & $308.78(3)$ & $P 2_{1} / n$ \\
\hline$(\mathrm{IX} \beta)$ & $5.077(4)$ & $6.268(6)$ & $5.379(9)$ & 90 & 113.2 & 90 & $157.3(5)$ & $P 2_{1}$ \\
\hline$(\mathrm{X} \alpha)$ & $6.774(1)$ & $7.795(2)$ & 9.803 (1) & $106.68(1)$ & 104.09 (2) & $92.29(1)$ & $477.6(2)$ & $P \overline{1}^{-}$ \\
\hline$(\mathrm{X} \beta)$ & $7.840(5)$ & $6.486(1)$ & $18.911(6)$ & 90 & 93.17 (3) & 90 & $960.2(7)$ & $P 2_{1} / n$ \\
\hline$(\mathrm{XI} \alpha)$ & $5.858(1)$ & 7.629 (1) & $28.237(3)$ & 90 & 97.97 (1) & 90 & $1249.7(3)$ & $P 2_{1} / c$ \\
\hline$(\mathrm{XI} \beta)$ & $5.962(1)$ & 7.267 (1) & $28.689(1)$ & 90 & $94.90(1)$ & 90 & $1238.4(3)$ & $P 2_{1} / c$ \\
\hline
\end{tabular}

molecular layers or crystal domains (Jeffrey \& Saenger, 1991), as demonstrated by the polymorphs (Table 3) of trans-2hydroxycycloheptanecarboxylic acid ( $\mathrm{V} b)$ (Kálmán et al., 2003). The possible stacking forms of pattern $\mathbf{7}$, together with the rearrangement $\mathbf{3} \rightarrow \mathbf{7}$ are described in Appendix $B$.

A curious property of the polymorphs of $(\mathrm{V} b)$ with their virtually identical unit cells is that their upper halves cannot be distinguished, while the lower halves differ by a $180^{\circ}$ rotation around a non-crystallographic axis perpendicular to the layers (Kálmán et al., 2003). In other words, if we rotate one of the unit cells around the $a$ axis, then the lower halves become identical while the upper halves differ by a rotation through 180. Consequently, dimorphs $(\mathrm{V} b)^{(p)}$ and $(\mathrm{V} b)^{(a)}$ [where ${ }^{(p)}$ and ${ }^{(a)}$ denote the parallel and antiparallel stackings] are isostructural in two dimensions with an alternating layer orientation; their polymorphism is the archetype of morphotropism. Explicitly, the polymorphs $(\mathrm{V} b)^{(p)}$ and $(\mathrm{V} b)^{(a)}$ differ simply in a $180^{\circ}$ rotation of every second layer in the unit cell. Such a phenomenon is rare, but not unique. While studying the isostructurality of polymorphs (Fábián \& Kálmán, 2004), we found that two $(\alpha$ and $\beta$ ) of the three polymorphs of glycine exhibit a similar relationship. In polymorph (IX $\beta$ ) (Table 3), the layers of $\mathrm{H}_{3} \mathrm{~N}^{+} \mathrm{CH}_{2} \mathrm{COO}^{-}$zwitterions, held together by four $\mathrm{N}-\mathrm{H}$... O hydrogen bonds, are stacked in the parallel mode, which gives rise to the space group $P 2_{1}$ (Iitaka, 1960). In polymorph (IX $\alpha$ ), with a unit cell doubled along the orthogonal $b$ axis, every second layer becomes antiparallel by a rotation through $180^{\circ}$. Since the molecules are achiral, this structure is centrosymmetric, space group $P 2_{1} /$ $n$ (Langan et al., 2002). These morphotropic polymorphs are also isostructural, with an alternating layer orientation in two dimensions.

\subsection{Rotation of molecules in a heterochiral chain}

The polymorphism of $(\mathrm{V} b)$ originates from the parallel stacking of the heterochiral chains of molecules (pattern 7) formed by antidromic rings (Appendix $A$ ). In contrast, the cis isomer $(\mathrm{V} a)$ crystallizes in the space group $C 2 / c$ (sub-pattern $3 \boldsymbol{b})$. However, as described in Appendix $B$, the sub-patterns $3 \boldsymbol{a}$ and $\mathbf{3 b}$ may be equally transformed into pattern $\mathbf{7}$ by a $180^{\circ}$ rotation of the molecules in every second chain in unison. From this, it follows that the stereoisomers $(\mathrm{V} a)$ and $(\mathrm{V} b)$ are also related via morphotropism.

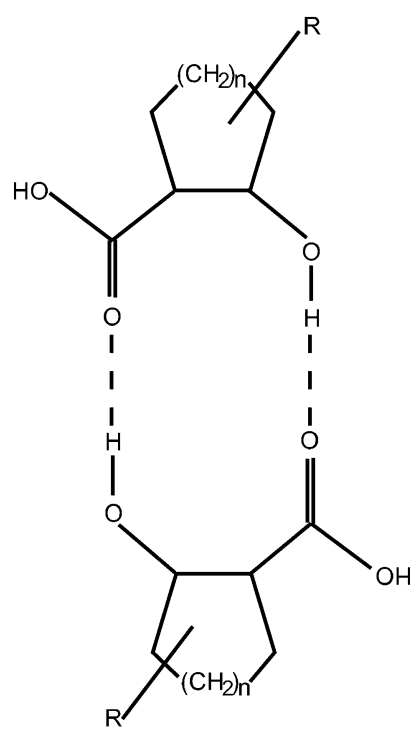

(a)
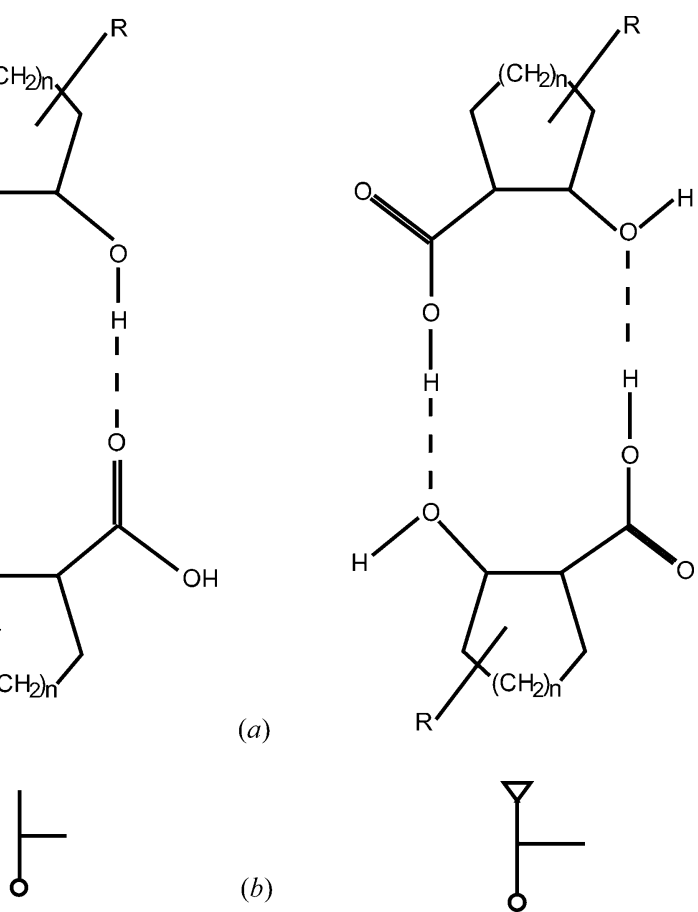

(b)

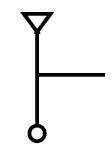

(c)
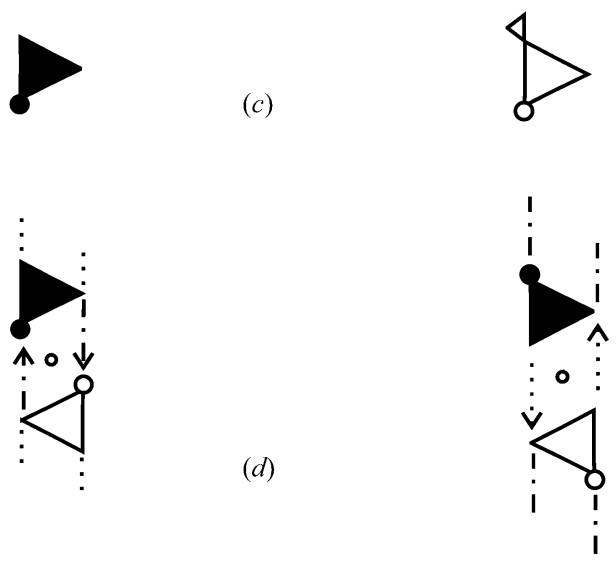

Figure 3

The basic forms of the OC (left) and $\mathrm{OH}$ (right) cyclic dimers observed for 2-hydroxycycloalkanecarboxylic acids and analogous carboxamides. Detailed explanations are given in the text. (Reproduced from Kálmán $e t$ al., 2002b.) 


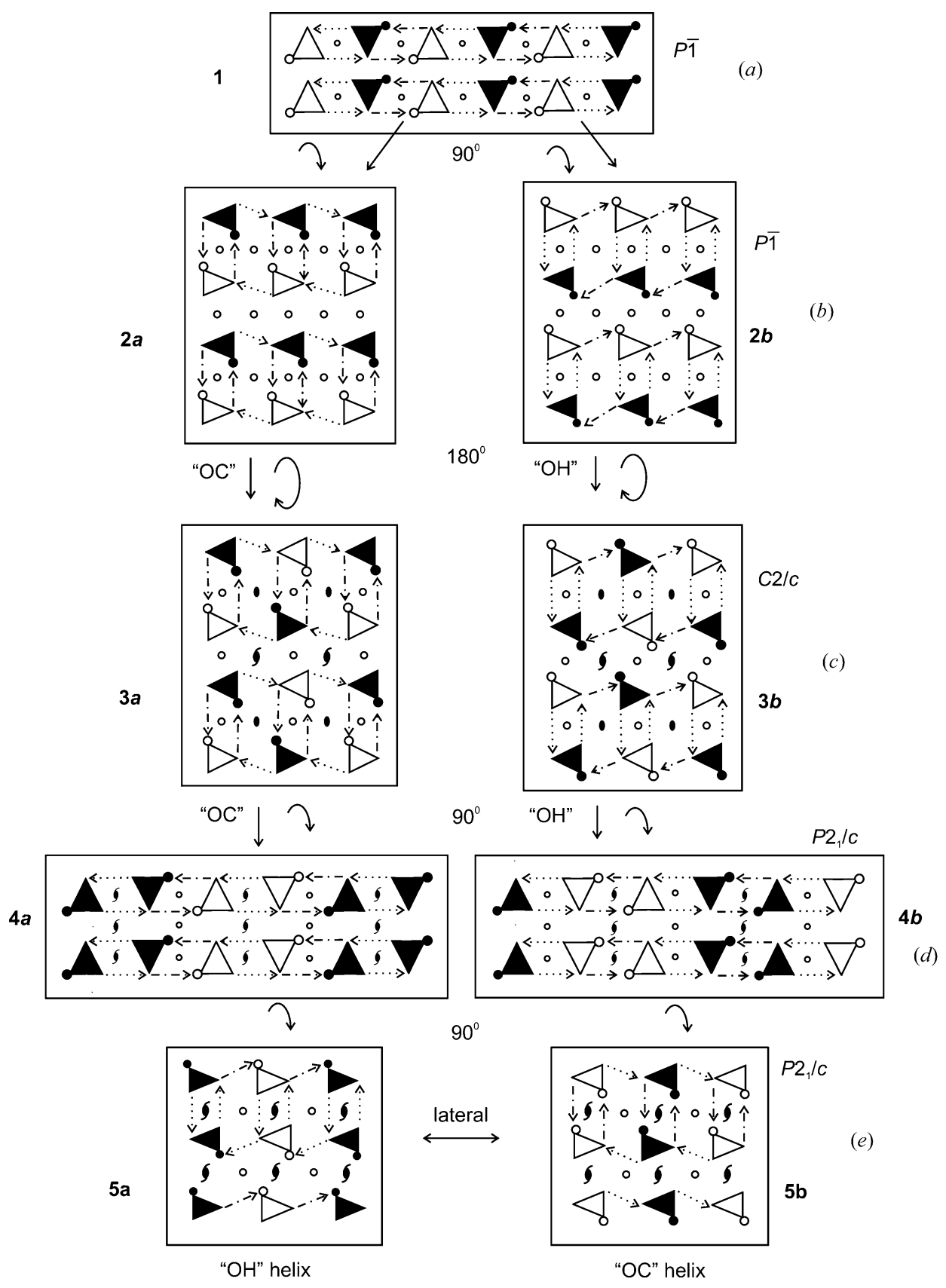

Figure 4

Topological patterns of the supramolecular self-organization of small molecules held together by their common hydrogen bonds. (a) Heterochiral dimers in a linear array (pattern 1); (b) OC and OH dimers in a lateral array (sub-patterns $\mathbf{2} \boldsymbol{a}$ and $\mathbf{2 b}$ ); (c) dimers in a lateral, but antiparallel array (sub-patterns $\mathbf{3} \boldsymbol{a}$ and $\mathbf{3 b}) ;(d)$ homochiral helices held together by heterochiral dimers in a linear array (sub-patterns $\mathbf{4} \boldsymbol{a}$ and $\mathbf{4 b}$ ); (e) enantiomeric helices, held together by tetramers in a lateral array (sub-patterns $\mathbf{5} \boldsymbol{a}$ and $\mathbf{5} \boldsymbol{b}$ ).

as nitrofurantoin (X) may also crystallize in two anhydrous ${ }^{6}$ forms, $\alpha$ and $\beta$ (Table 3), obtained either from hot acetic acid-water or from hot acetone solution (Pienaar et al., $1990 b)$. In the monoclinic polymorph $(\mathrm{X} \beta)$, the molecules form infinite helices held together by $\mathrm{N}-\mathrm{H} \cdots \mathrm{O}$ hydrogen bonds (Fig. $7 a$ ). If the achiral molecules, similarly as in the rearrangement $\mathbf{3} \boldsymbol{a} \Rightarrow$ 7 (see Appendix $B$ ), rotate through $180^{\circ}$ on either side of the twofold screw axis in unison, they form centrosymmetric $R_{2}^{2}(8)$ dimers with the molecules stacked on the other side of the disappearing helix in $(\mathrm{X} \alpha)$ (Fig. 7b). Overall, the phase transition between the nitrofurantoin polymorphs $(\mathrm{X} \alpha)$ and $(\mathrm{X} \beta)$, mediated by the solvents, is a real rotation of the molecules.

2.5.2. Polymorphism via noncrystallographic rotation of a macroring. Two polymorphs of trans-13-azabicyclo[10.2.0]-

tetradecan-13-one (XI) present a unique example of isostructurality, differing only in the orientation of a given hydrogen bond with respect to the $\beta$-lactam bond (Fábián et al., 2004). This slight difference is attributable to the twofold rotation of the $\mathrm{C}_{12} \mathrm{H}_{22}$ ring of $C_{2}$ symmetry, which is hardly noticeable in the crystal structure. Both polymorphs are monoclinic (space group $P 2_{1} / c$ ) and their orthogonal axes accommodate the homochiral helices of azetidin-2-one moieties linked by $\mathrm{N}-\mathrm{H} \cdots \mathrm{O}$ hydrogen bonds. The $b$ axis is considerably longer in $(\mathrm{XI} \alpha)$ $[7.629(1) \AA]$ than in $(\mathrm{XI} \beta)$ [7.267 (1) $\AA$ ], which is attributed to the different orientations of the $\mathrm{O}$ lone-pair electrons that accept the hydrogen bond. The hydrogenbond arrangement may be either antiperiplanar $(\mathrm{XI} \alpha)$ or synperi-

\subsection{Rotation of molecules in different patterns}

2.5.1. Polymorphism of planar molecules. Polymorphism is often attributable to the conformational difference(s) assumed by a molecule under different circumstances (solvent, pressure, temperature etc.). However, planar molecules such

\footnotetext{
${ }^{6}$ Nitrofurantoin also forms two monohydrates, described by Pienaar et al. (1990a).
}

planar $(\mathrm{XI} \beta)$ with respect to the endocyclic amide bond of the planar $\beta$-lactam ring. The formation of (XI $\alpha)$ and $(\mathrm{XI} \beta)$ from different solvents (methanol versus acetone) is facilitated by the almost perfect $C_{2}$ symmetry of the 12 -membered rings (Figs. $8 a$ and $b$ ). A non-crystallographic rotation of the molecules through $180^{\circ}$ around the molecular $C_{2}$ axis tilted by ca $45^{\circ}$ with respect to the twofold screw axis alters only the orientation of the $\mathrm{O}=\mathrm{C}-\mathrm{N}-\mathrm{H}$ moiety. The polymorphs 
$(\mathrm{XI} \alpha)$ and $(\mathrm{XI} \beta)$ (Table 3$)$, characterized by a high degree of isostructurality (unit-cell similarity index $\Pi=0.008$, volumetric index $I_{v}=75 \%$; Fábián \& Kálmán, 1999), are again related by a non-crystallographic rotation of the $\beta$-lactam molecules.

2.5.3. Non-crystallographic rotations in oblique unit cells.

(i) The four unit cells (space group, $P \overline{1}$ ) of the $c i s$-alicyclic $\beta$ amino acids $[(\mathrm{XII} a) \rightarrow(\mathrm{XV} a)]$ display the superposition of patterns $\mathbf{1}$ and $\mathbf{2 b}$ (in the following, pattern $\mathbf{8}$ ). Nevertheless, while the dimers of (XII $a)$, (XIII $a$ ) and (XIVa) exhibit a high degree of isostructurality, with the same orientation in the oblique unit cells, the dimer of $(\mathrm{XV} a)$ rotates through $180^{\circ}$ around a non-crystallographic axis parallel to the $c$ axis (Fábián et al., 2005). The different dimer orientations [(XVa) versus $(\mathrm{XII} a) \rightarrow(\mathrm{XIV} a)]$ in the oblique unit cells, denoted by sub-patterns $8 \boldsymbol{a}$ and $\mathbf{8 b}$ (Table 2), account for an improved close packing of $(\mathrm{XVa})$ bearing the largest cycloalkane ring. Consequently, (XVa) is homostructural (Kálmán et al., 1993b) with (XII $a),(\mathrm{XIII} a)$ and (XIVa). However, this basic form of

(a)

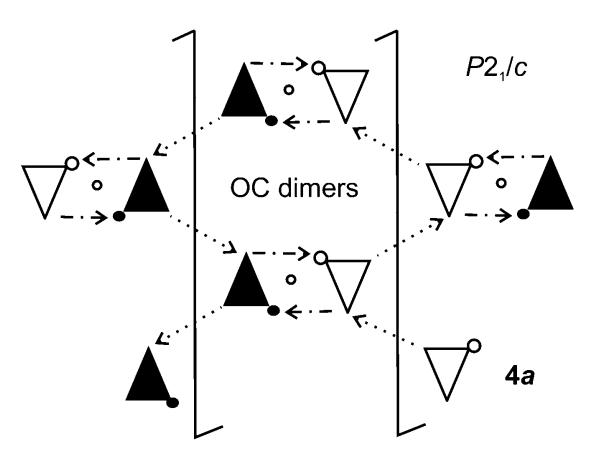

la

$(d)$

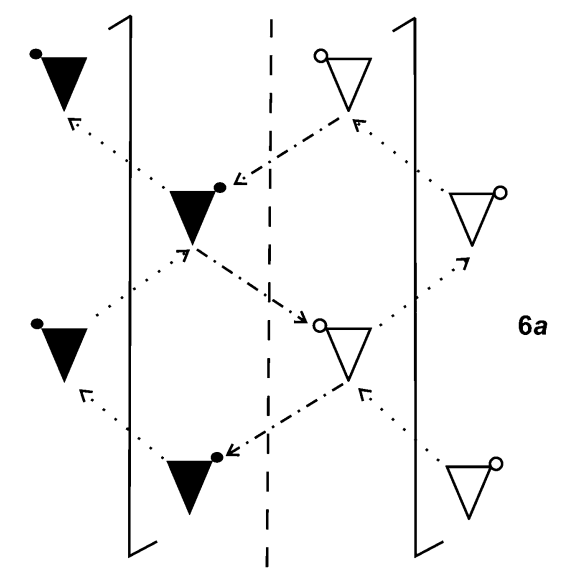

Figure 5

(a) and (b) Two-dimensional description of helices held together by dimers in an antiparallel array (subpatterns $\mathbf{4} \boldsymbol{a}$ and $\mathbf{4 b}$ ) or $(c)$ and $(d)$ separated by glide planes in a parallel array (sub-patterns $\mathbf{6} \boldsymbol{a}$ and $\mathbf{6} \boldsymbol{b}$ ). Sub-pattern $\mathbf{6} \boldsymbol{a}$ has not been observed in crystals so far.

(c)

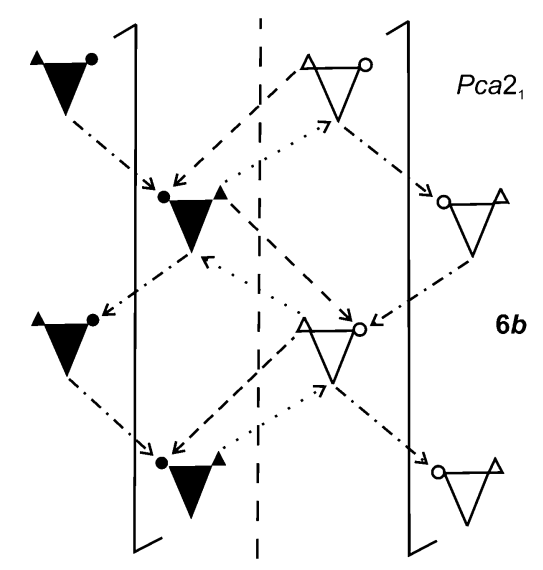

morphotropism compelled us to identify similar phenomena in other crystals we studied earlier.

(ii) To present comparable stereoviews of the packing similarity of (III $b),(\mathrm{IV} a)$ and $(\mathrm{V} a)$, the unit cell of $(\mathrm{V} a)$, determined with the space group $C 2 / c$, was transformed into a body-centered form with the non-standard space group $I 2 / \mathrm{c}$ (cf. Fig. 8 in Kálmán et al., 2002a). From this it follows that the isostructurality of ( $\mathrm{V} a$ ) differs from that of (III $b$ ) and (IV $a$ ) by a rotation of the $\mathrm{OH}$ dimers through $180^{\circ}$ in the oblique unit cell.

(iii) In one of our earlier observations (Kálmán et al., 1993b), 5- and 7-chloroindol-3-ylacetic acids (Kojic Prodic et al., 1992) were described as homostructural in their oblique unit cells. These substitutional isomers were found to have similar close packing via a non-crystallographic symmetry ( $c f$. Fig. 10 in Kálmán et al., 1993b). These isomers can also be regarded as morphotropes, related by an approximately $180^{\circ}$ virtual rotation of the molecules around the shorter diagonal of the oblique $a c$ plane.

(iv) At the beginning of these investigations, we reported (Kálmán el al., 2000) on the peculiar isostructurality of $\left(1 R^{*}, 2 S^{*}, 4 S^{*}\right)$-4-tert-butyl-2-

hydroxycyclopentanecarboxylic acid (II $a$ ) with its tert-butyl free carboxamide derivative (VII $a$ ). Although the molecules differ in the tert-butyl group and the $\mathrm{CONH}_{2}$ vs $\mathrm{COOH}$ functions, their close packing is similar if one of the oblique unit cells rotates through $180^{\circ}$ by a turn of the orthogonal crystal axis upside down ( $c f$. Fig. 14 in Kálmán et al., 2001).

2.6. Non-crystallographic rotations in alicyclic $\beta$-amino acids

We have seen that the isostructurality of cis-alicyclic $\beta$-amino acids [(XII $a),(\mathrm{XIII} a)$ and (XIVa)] is differentiated by a rotation of the $(\mathrm{XVa})$ dimers through $180^{\circ}$ around a non-crystallographic axis in their oblique unit cells (Fábián et al., 2005). We now show that these $\beta$-amino acids are also linked to their stereoisomers and unsaturated derivatives by other virtual rotations, as follows:

After successful syntheses and crystallizations, the study of the cyclohexane homolog (XIII $a$ ) could be extended to its trans 
isomer (XIII $b)$ and their cyclohexene derivatives (XVI $a$ ) and (XVIb). Since they form zwitterions, each $\mathrm{NH}_{3}^{+}$moiety forms three hydrogen bonds of the $\mathrm{OC}$ type with carboxylic $\mathrm{O}$ atoms, one of which is bifurcated. Two infinite rows of the heterochiral $R_{2}^{2}(12)$ dimers of (XIII $a$ ), depicted by the topological symbols in Fig. 9(a), are held together by two hydrogen bonds and crosslinked by the third hydrogen bond. In this twodimensional network, two kinds of centrosymmetric tetramers, $R_{4}^{4}(12)$ and $R_{4}^{2}(8)$, furnish the lateral connections between the ribbons. A rotation of every second dimeric motif in pattern $\mathbf{8}$ through $180^{\circ}$ generates homochiral dimers (Fig. 9b), which polymerize into antiparallel helices (Fig. 9c). In this stacking (pattern 9), the homochiral 'triangles' are located around a twofold screw axis and linked together by two hydrogen bonds (dotted lines) with alternating orientations. The $R_{2}^{2}(12)$ dimers formed along the helices are free of symmetry. The enantiomeric helices are crosslinked again by the third hydrogen bond, preserving the alternating $R_{4}^{4}(12)$ and $R_{4}^{2}(8)$ tetramers from the pattern 8 . The antiparallel helices held together by the tetramers of $C_{i}$ symmetry form a layer perpendicular to the folded plane of $\mathbf{8}$. This novel pattern 9 is exemplified by three crystal structures, (XIIIb) and the cis-trans isomers of (XVI), described above.

A comparison of the structures [(XIII $a),(\mathrm{XIII} b)]$ and $[(\mathrm{XVI} a),(\mathrm{XVI} b)]$ reveals an important relationship between them:

(i) (XIII $a)$ and its stereoisomer (XIII $b$ ) are linked by the type of virtual rotation $\mathbf{8} \rightarrow \mathbf{9}$.

(ii) Similarly, (XIII $a$ ) and its cyclohexene derivative (XVI $a$ ) are linked by the same type of rotation $\mathbf{8} \rightarrow \mathbf{9}$.

(iii) Additionally, their trans isomers (XIII $b)$ and (XVIb) are isostructural.

Although the unit cells of the stereoisomers [(XVI $a),(\mathrm{XVI} b)]$ are rather similar $(\Pi=0.011$; Fábián \& Kálmán, 1999), the crystals should differ. From this it follows that pattern 9 must have alternative sub-patterns, $\boldsymbol{9} \boldsymbol{a}$ and $\mathbf{9 b}$ (Table 2), which differ by a non-crystallographic rotation of the helical motif along the $a$ axis in the oblique unit cell of either (XVI $a$ ) or (XVI $b$ ) (Fig. 10). Overall, this difference in the locations of the stereoisomers in an oblique unit cell serve to optimize their close packing.
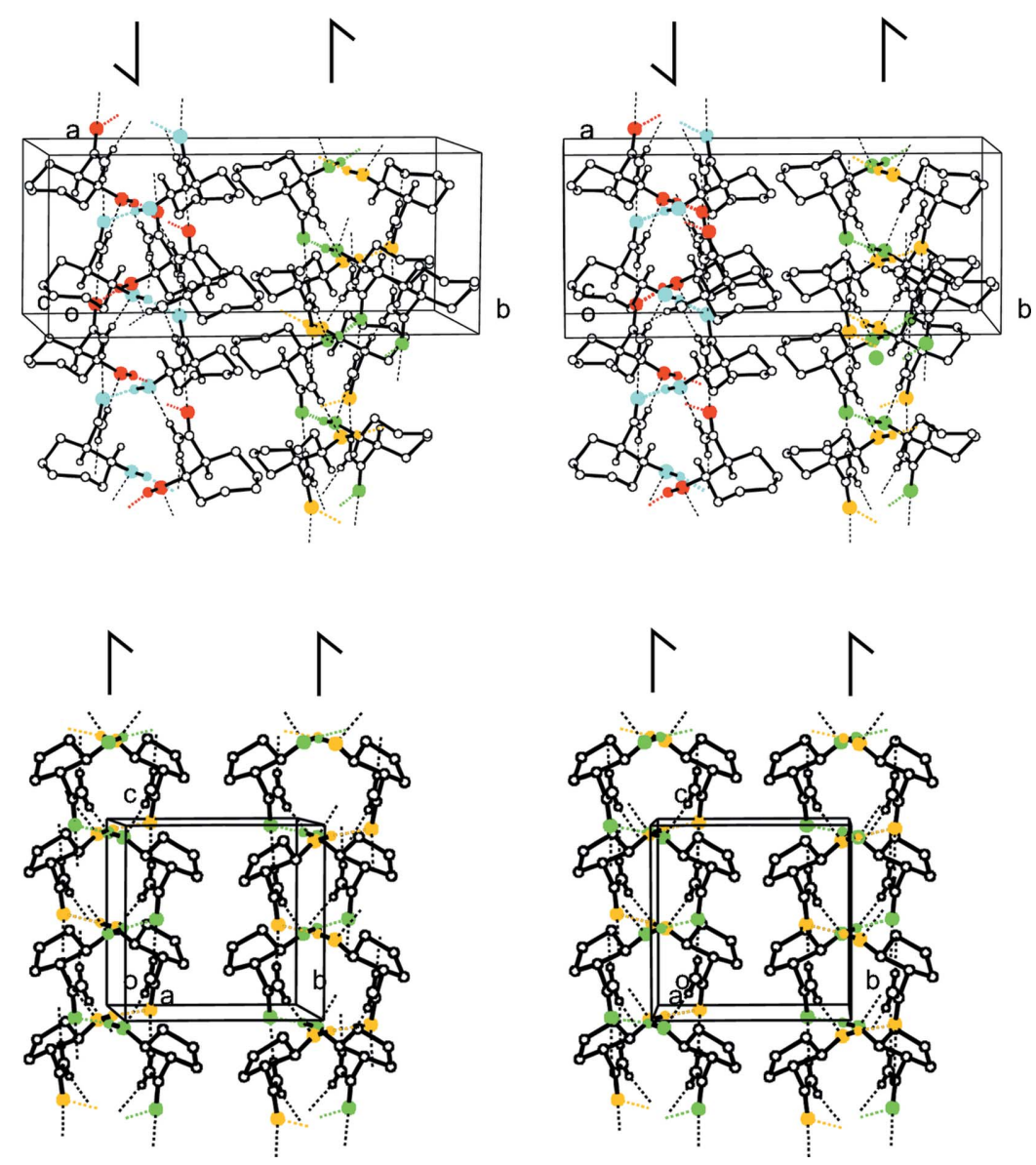

Figure 6

Stereoview of the close packing of (VII $b)$ and (VIII $b)$. The alternating two-dimensional isostructurality is revealed by the antiparallel helices in (VIII $b$ ) versus the parallel helices in (VII $b)$. In both structures, the enantiomers denoted by $4 R$ are held together by the hydrogen bonds shown in green, whereas the helices with $4 S$ configuration are shown by yellow hydrogen bonds. The antiparallel double helix in (VIII $b$ ) is indicated in blue (4R) and red (4S). (Reproduced from Kálmán et al., 2004.)

\section{Conclusions}

It has been demonstrated that several of the hydrogen-bonded crystal structures of disubstituted cycloalkanes are related by non-crystallographic rotations of their basic motifs (dimers, helices, ribbons and tetramers). They form a network which relates directly or indirectly to the packing patterns. This fact-gathering work was complemented by a small number of examples taken from the literature. Accordingly, morphotropism involves the rotation of motifs which transforms one packing pattern into another and vice versa.

The forms of morphotropism that have been observed were as follows:

(i) A rotation of identical motifs through 90 or $180^{\circ}$ in unison, e.g. (i) hydrogen-bonded molecules rotate upside down in a helix, (ii) or all dimers rotate by $90^{\circ}$ around their main axis in unison.

(ii) A rotation of every second motif of a packing pattern through $90^{\circ}$ or $180^{\circ}$, e.g. (a) every second dimeric motif in a lateral array rotates around its center of symmetry through $180^{\circ}(b)$ or hydrogen-bonded molecules (in the case of polymorphism) rotate upside down in unison, but only on either side of the respective twofold screw axis.

(iii) A rotation of the whole pattern through $180^{\circ}$, e.g. a $180^{\circ}$ rotation of infinite layers of hydrogen-bonded tetramers upon each other forming either antiparallel or parallel layer stacking. The axis of such a rotation may be perpendicular to [dimorphs $(\mathrm{V} b)^{(p)}$ and $(\mathrm{V} b)^{(a)}$ ] 
or tilted with respect to a screw axis [dimorphs $(\mathrm{XI} \alpha)$ and $(\mathrm{XI} \beta)]$ or parallel to a direction in an oblique unit cell [(XII $a)_{-}$ (XIVa) versus $(\mathrm{XV} a)]$.

Although the present work still comprises predominantly fact-gathering, it ascertains that two or more crystals are morphotropes if their packing patterns differ only by one (or occasionally two) non-crystallographic rotation(s) of their common motifs. In other words, the packing patterns of

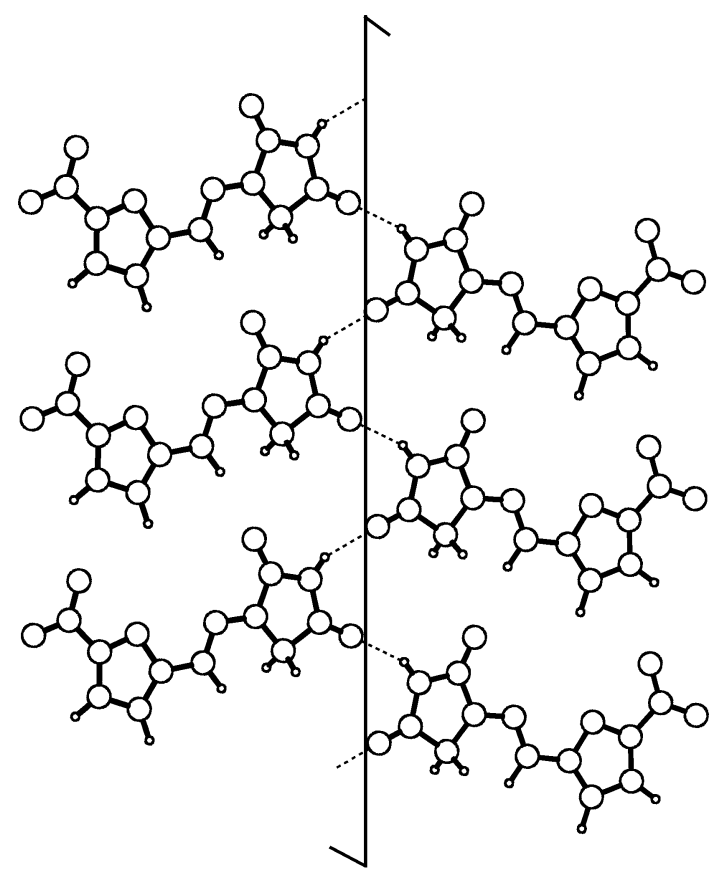

(a)

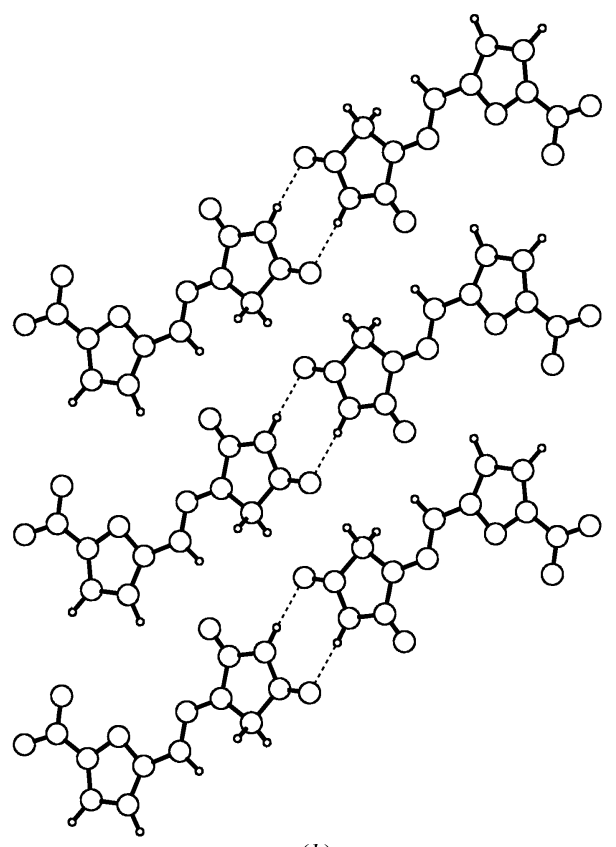

(b)

Figure 7

The triclinic $(\mathrm{X} \alpha)$ and monoclinic $(\mathrm{X} \beta)$ polymorphs of nitrofurantoin (Pienaar et al., 1990a). A $180^{\circ}$ rotation of the molecules on the right side of the helix (Fig. 6a) perpendicular to the twofold screw axis results in a rearrangement which forms $R_{2}^{2}(8)$ dimers in the triclinic unit cell (Fig. 7b). chemically similar molecules with isometric shapes may be related by a few non-crystallographic rotations. In particular, stereoisomers form crystals, the patterns of which differ only in a non-crystallographic rotation. It explains how cis and trans isomers, with a configurational difference, are able to form closely related packing patterns. Homostructural crystals may also show morphotropism whenever the 'second' layer rotates through $180^{\circ}$, or the whole pattern rotates through $180^{\circ}$ in an oblique unit cell.

The most important discovery is the morphotropism of polymorphs. While two chemically similar (isomeric or homostructural) crystals are related by a virtual rotation of the common motif, such a non-crystallographic rotation between polymorphs really transforms one molecule into another. The four rather different morphotropic polymorphs described above (Table 3) are enantiotropic, i.e. their reversible phase transitions are solvent-mediated.

Finally, it is also noteworthy that the revealed forms of noncrystallographic rotations occur in the most frequent centrosymmetric space groups $P 2_{1} / c$ (12), $P \overline{1}(7), C 2 / c$ (3) and $P b c a$ (1), followed by $P n a 2_{1}$ (2) and $P c a 2_{1}$ (1). Even their numbers (in parentheses) among the structures discussed above correspond roughly to the population (\%) of these space groups archived in the Cambridge Structural Database (CSD; October 1997 issue; Allen, 2002): 35.4, 19.4, 7.2, 3.8, 1.54, $0.73 \%$, as demonstrated by statistics reported earlier by

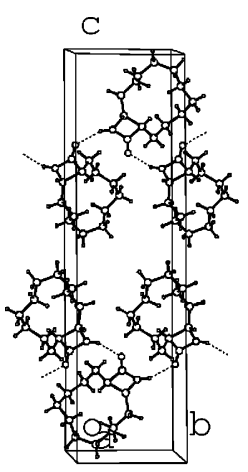

(a)
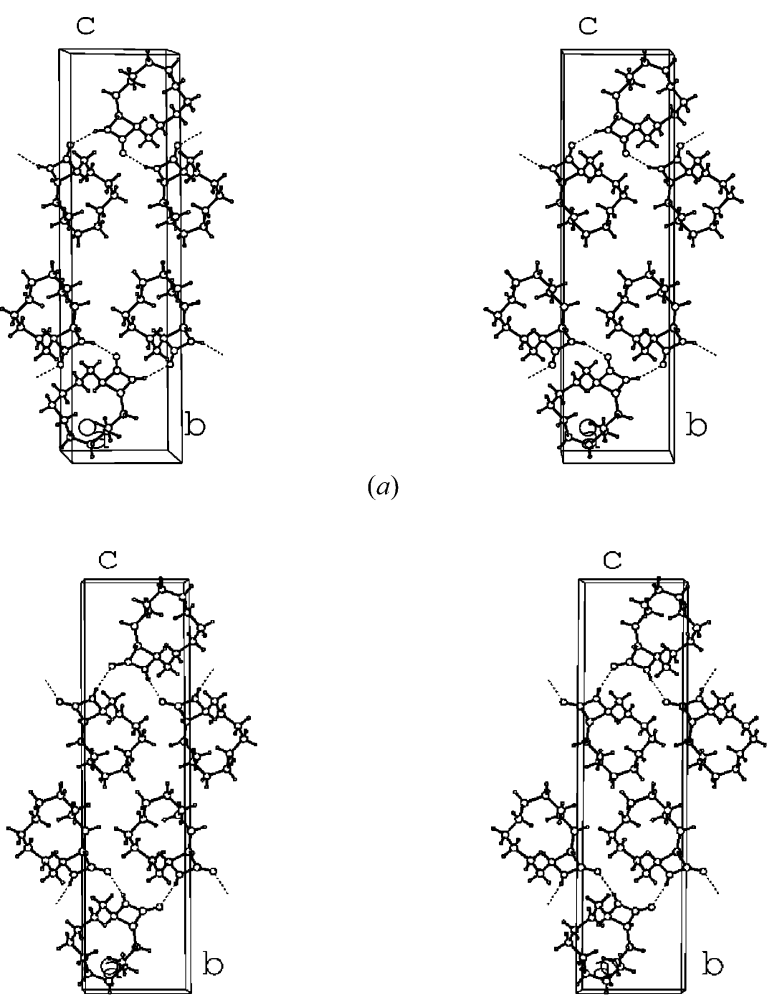

Figure 8

(b)

Stereoviews of the close packing of the polymorphs $\alpha$ and $\beta$ of (XI) in space group $P 2_{1} / c$. In the unit cells $(a)$ and $(b)$, the positions of the cyclododecane rings are the same; only the positions of the $\mathrm{C}=\mathrm{O}$ and $\mathrm{N}-\mathrm{H}$ groups are interchanged. (Reproduced with kind permission from Fábián et al., 2004.) 
Kálmán (1999). This observation once again underscores the fundamental connections between the most frequent space groups (Brock \& Dunitz, 1994). This conclusion is substantiated by the variety (four) of close packing in the space group $P 2_{1} / c$ found between the investigated disubstituted cycloalkanes. Enantiomeric helices are crosslinked:

(i) by dimers (pattern 4) (I $a$ ) and (VI $a$ );

(ii) by tetramers (pattern 5) (II $a$ ) and (VII $a$ );
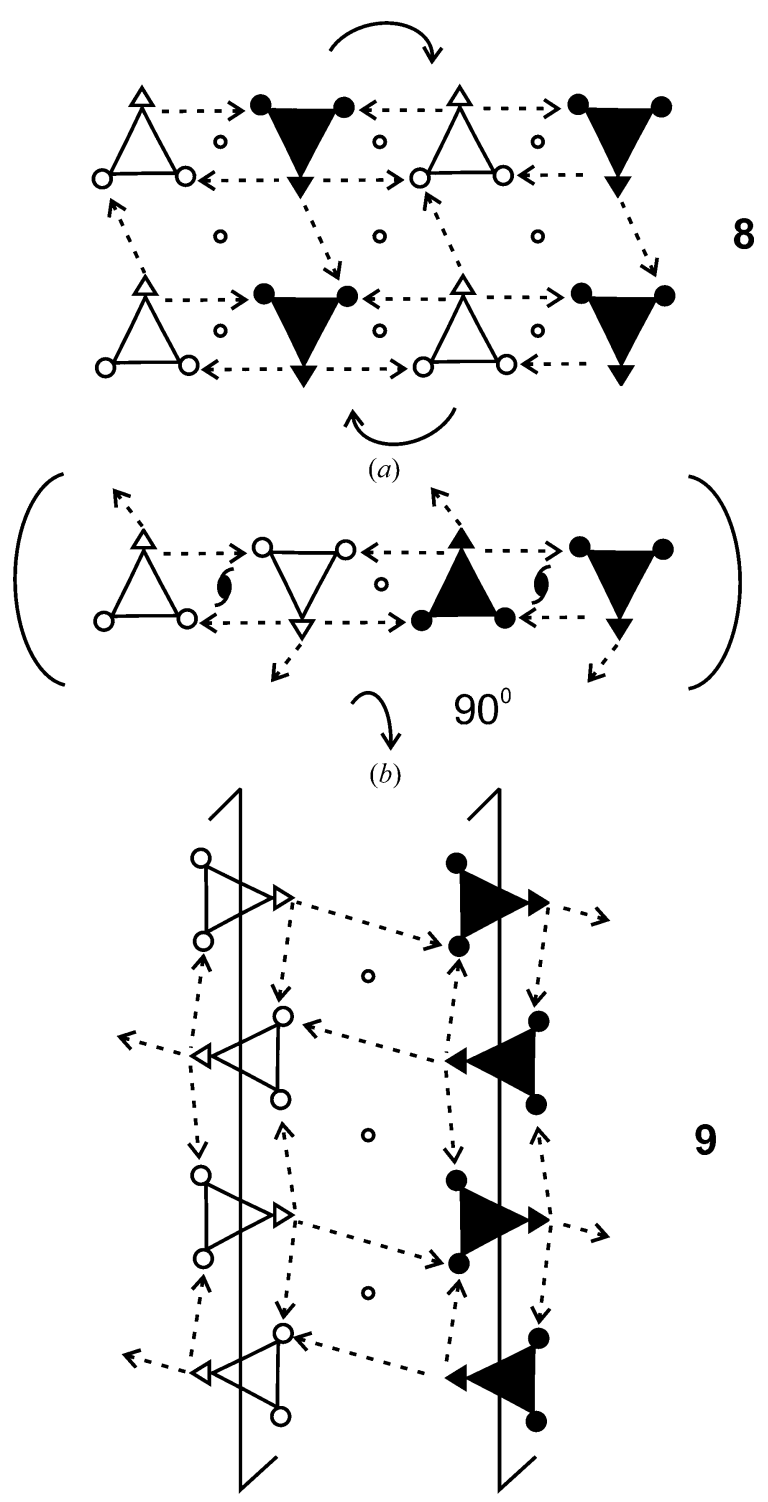

(c)

\section{Figure 9}

Topological presentation of the close packing of cis-alicyclic $\beta$-amino acids $(a)$ and the results of the type of rotation $8 \rightarrow 9$ in one $(b)$ and two dimensions $(c)$. Since $\beta$-amino acids are zwitterions, their symbolic presentation denotes the $\mathrm{NH}_{3}^{+}$group with a small triangle rotated through $180^{\circ}$ to that of $\mathrm{NH}_{2}$ groups in carboxamides, depicted in Fig. 3(b), while the $\mathrm{COO}^{-}$moiety is denoted by two small circles. The molecules forming helices are linked by two $\mathrm{NH}$... O hydrogen bonds along the twofold screw axes. They enclose symmetry-free $R_{2}^{2}(8)$ dimers. The enantiomeric helices are cross-linked by the third $\mathrm{N}-\mathrm{H} \cdots \mathrm{O}$ hydrogen bond, simultaneously enclosing the $R_{4}^{4}(12)$ and $R_{4}^{2}(8)$ tetramers. (iii) by two kinds of tetramer (sub-pattern 9a) (XIIIb), (XVI $a)$ and (XVI $b)$;

(iv) or they are perpendicular to the layers formed by heterochiral tetramers (pattern 7) (IIc).

These remarks and the observations described above suggest that the standard forms of the 230 space groups are no longer enough to describe structural properties ( $c f$. the transitional space groups between triclinic and pseudo-monoclinic crystals described in Kálmán, 1998; Kálmán \& Argay, 1998). Thus, the

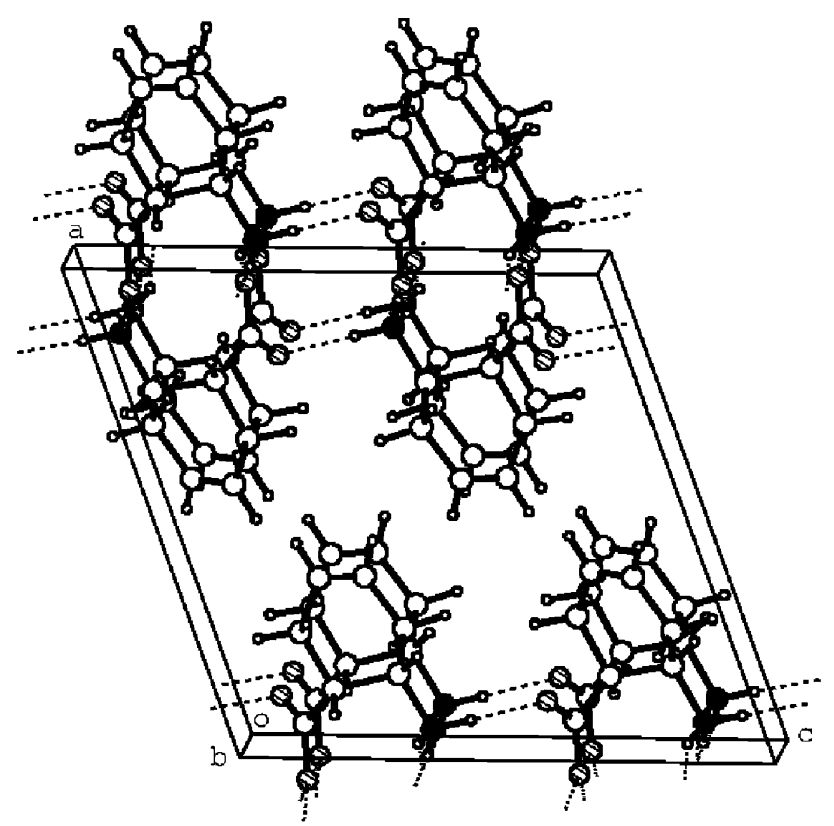

(a)

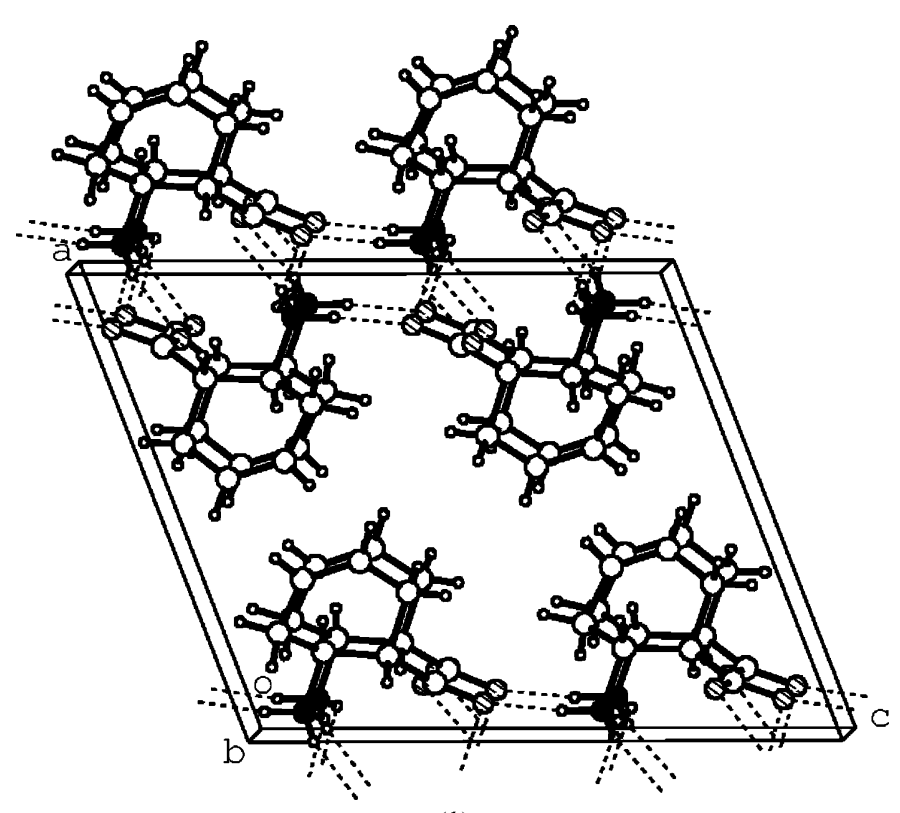

(b)

Figure 10

Projections of the unit cells of the cis and trans isomers of 2aminocyclohex-4-enecarboxylic acids (XVI $a$ ) and (XVIb) (Fábián et al., 2005). Apart from configurational differences in the helix formation, they differ by a $180^{\circ}$ rotation of the helices parallel to the $a$ axis in either of the two (slightly different) oblique unit cells. 
use of non-standard space groups such as $P 2_{1} / n, I 2 / c, P n 2_{1} a$, etc. is not only a matter of choice of the three principal axes. Each of them has its meaning in describing a relevant structural relationship. For example, the non-standard space group $I 2 / c$ versus $C 2 / c$ indicates the virtual rotation of the common motif between (IVa) and ( $\mathrm{V} a$ ) in their 'isomorphous' obligue unit cells. No such distinction can be made, however, between the close packings of $(\mathrm{XIV} a)$ versus $(\mathrm{XVa})$ in the triclinic (space group $P \overline{1})$ and $(\mathrm{XVI} a)$ versus $(\mathrm{XVI} b)$ in the monoclinic unit cells (space group $P 2_{1} / c$ ). From these it follows that we must become accustomed to an increasingly generalized description of crystals, as suggested by Desiraju (2003).

As far as the future is concerned, the author hopes that the differences in the crystal structures of similar molecules will be
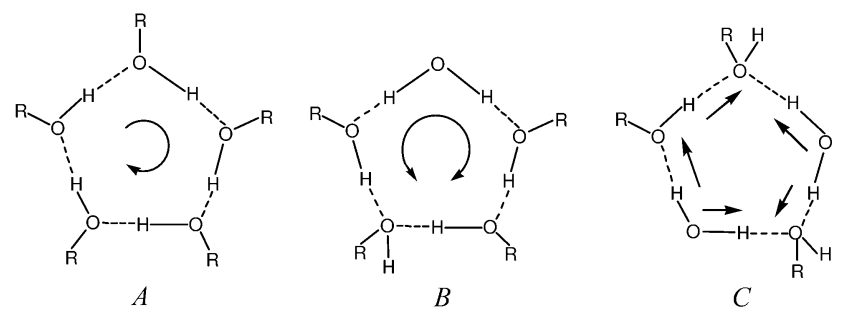

Figure 11

Homo-, anti- and heterodromic rings.

(a)
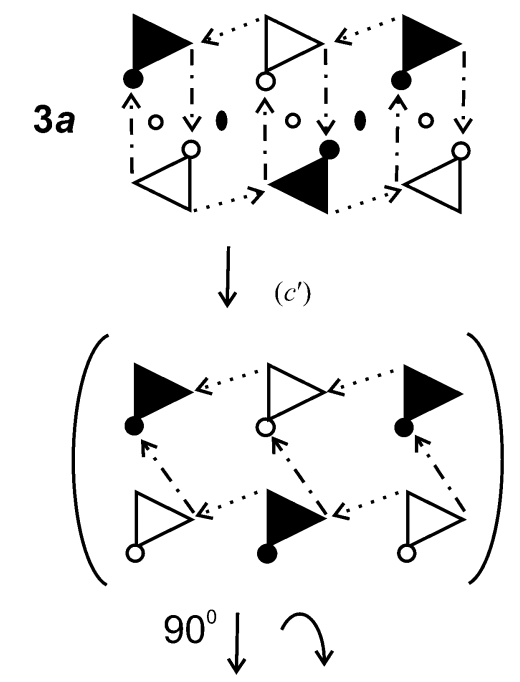

$7 a$

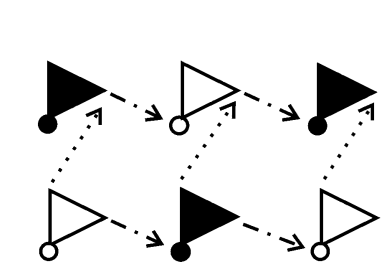

(c)

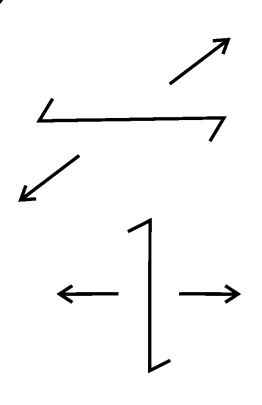

2
$3 b$
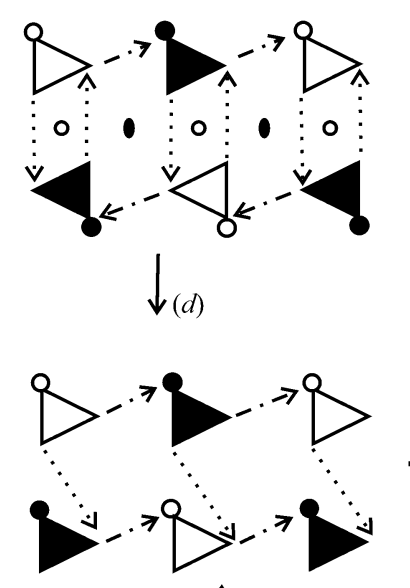

$7 b$

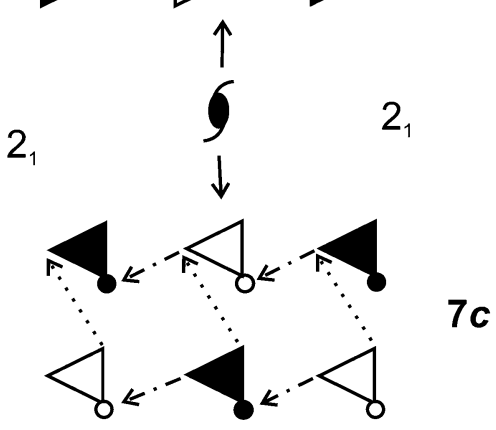

(e)
Figure 12

The parent sub-patterns $(a) \mathbf{3} \boldsymbol{a}$ and $(b) \mathbf{3} \boldsymbol{b}$, and $(c),\left(c^{\prime}\right),(d)$ and $(e)$ four different settings of pattern $\mathbf{7}$ formed by antidromic rings described by the graph-set notation $R_{4}^{4}(18)$. better understood from studies of non-crystallographic rotations, whenever they are recognized. Since such a study has not been made so far, a search for such rotations, hopefully in numerous crystals archived in the CSD, may be informative in crystal engineering.

\section{APPENDIX $A$}

Definition of the homo-, hetero- and antidromic rings formed by hydrogen bonds of the type $\mathrm{O}-\mathrm{H} \cdots \mathrm{O}$

The homodromic $(A)$, antidromic $(B)$ and heterodromic $(C)$ rings for cyclodextrin hydrates defined in the book ' $H y d r o g e n$ Bonding in Biological Structures' (Jeffrey \& Saenger, 1991, p. 38) may be seen in Fig. 11. These definitions for pentamers have been adapted for the tetramers observed in the structures discussed here.

\section{APPENDIX $B$}

Dipole extinctions in antidromic rings via three forms of layer stacking

The simplest stacking form is an overlap of the identical subpatterns $\mathbf{7} \boldsymbol{a}$ and $\mathbf{7 b}$ (Figs. $12 c$ and $d$ ), deduced from $\mathbf{3} \boldsymbol{a}$ and $\mathbf{3 b}$ (Figs. $12 a$ and $b$ ) by a rotation of each molecule in their second row through $180^{\circ}$. They are held together by a twofold screw axis which leaves the ring dipoles parallel [polymorph $(\mathrm{V} b)^{(p)}$, space group $\left.P n a 2_{1}\right]$. Consequently, the antiparallel alignment of the domains cancels out the dipole moment. The second form [polymorph $\left.(\mathrm{V} b)^{(a)}\right]$ is an overlap of the identical $\mathbf{7} \boldsymbol{a}$ and $\mathbf{7 c}$ (Figs. $12 c$ and $e$ ) held together by a screw axis perpendicular to the dipole vector which leaves the ring dipoles antiparallel. To this form a nonstandard space group $P n 2_{1} a$ had to be ascribed (Kálmán et al., 2003). The third form - demonstrated by (IIc) $\left(1 R^{*}, 2 S^{*}, 5 R^{*}\right)$-5-tert-butyl-2hydroxycyclopentanecarboxylic acid (Kálmán et al., 2001) - is an overlap of the identical subpatterns $\mathbf{7 b}$ and $\mathbf{7 c}$ (Figs. $12 d$ and $e$ ), held together by the twofold screw axes which are perpendicular to them.

The author thanks his colleagues for their invaluable help in the structure determinations $(\mathrm{Mr}$ Gyula Argay and $\mathrm{Mr}$ Csaba Kertész), evaluations (Dr László Párkányi) and presentations (Mrs Györgyi Tóth-Csákvári). Thanks 
are due to Professor Gábor Bernáth and Dr Zsuzsanna Cs. Gyarmati for the crystals. I wish to thank in particular my student Dr László Fábián, who helped me greatly in writing the papers cited above and with the ongoing evaluation of novel results in our efforts to solve the puzzle posed by Kitaigorodskii 50 years ago. Dr Zsigmond Ritoók (Professor of Greek and Latin at the University of Budapest) also deserves the author's thanks for the definition of the word 'morphotropic' from the Greek roots. This work was supported by Hungarian Research Fund, grants OTKA T034985 and T049712.

\section{References}

Allen, F. H. (2002). Acta Cryst. B58, 380-388.

Bernstein, J., Davis, R. E., Shimoni, L. \& Chang, N.-L. (1995). Angew. Chem. Int. Ed. Eng. 34, 1555-1573.

Brock, C. P. \& Dunitz, J. D. (1994). Chem. Mater. 6, 1118-1127.

Dahlén, B. (1974). Acta Cryst. B30, 647-651.

Desiraju, G. R. (2003). Nature, 423, 485.

Etter, M. C. (1990). Acc. Chem. Res. 23, 120-126.

Fábián, L. \& Kálmán, A. (1999). Acta Cryst. B55, 1099-1108.

Fábián, L. \& Kálmán, A. (2004). Acta Cryst. B60, 547-588.

Fábián, L., Kálmán, A., Argay, Gy., Bernáth, G. \& Gyarmati, Zs. Cs. (2004). Chem. Commun. pp. 2114-2115.

Fábián, L., Kálmán, A., Argay, Gy., Bernáth, G. \& Gyarmati, Zs. Cs. (2005). Cryst. Growth Des. 5, 773-782.

Hargittai, I. \& Kálmán, A. (1993). Acta Chim. Hung. 130, 151-577.

Iitaka, Y. (1960). Acta Cryst. 13, 35-45.

Jeffrey, G. A. \& Saenger, W. (1991). Hydrogen Bonding in Biological Structures. Berlin, Heidelberg: Springer Verlag.

Kálmán, A. (1998). Bull. Czech Slovak Cryst. Ass. 5, 153-154 (Abstracts, ECM-18, Prague).

Kálmán, A. (1999). Magyar Tudomány, pp. 280-288 (in Hungarian). Kálmán, A. \& Argay, Gy. (1998). Acta Cryst. B54, 877-888.

Kálmán, A., Argay, Gy., Fábián, L., Bernáth, G. \& Fülöp. F. (2001). Acta Cryst. B57, 539-550.
Kálmán, A., Fábián, L. \& Argay, Gy. (2000). Chem. Commun. pp. 2255-2256.

Kálmán, A., Fábián, L., Argay, Gy., Bernáth, G. \& Gyarmati, Z. (2002a). Acta Cryst. B58, 494-501.

Kálmán, A., Fábián, L., Argay, Gy., Bernáth, G. \& Gyarmati, Z. (2002b). Acta Cryst. B58, 855-863.

Kálmán, A., Fábián, L., Argay, Gy., Bernáth, G. \& Gyarmati, Zs. (2003). J. Am. Chem. Soc. 125, 34-35.

Kálmán, A., Fábián, L., Argay, Gy., Bernáth, G. \& Gyarmati, Z. Cs. (2004). Acta Cryst. B60, 755-762.

Kálmán, A. \& Párkányi, L. (1997). Adv. Mol. Struct. Res. 3, 189-226.

Kálmán, A., Párkányi, L. \& Argay, Gy. (1993a). Acta Chim. Hung. 130, 279-298.

Kálmán, A., Párkányi, L. \& Argay, Gy. (1993b). Acta Cryst. B49, 1039-1049.

Kálmán, A., Sasvári, K. \& Kapovits, I. (1973). Acta Cryst. B29, 355357.

Kitaigorodskii, A. I. (1961). Organic Chemical Crystallography, pp. 222-231. New York: Consultants Bureau.

Kojic Prodić, B., Nigović, B., Tomić, S. \& Duax, W. L. (1992). Abstr. of the Annual Meeting of Am., 9-14 August 1992, Pittsburgh, p. 111.

Langan, P., Mason, S. A., Myles, D. \& Schoenborn, B. P. (2002). Acta Cryst. B58, 728-733.

Pannell, K. H., Kapoor, R. N., Raptis, R., Párkányi, L. \& Fülöp, V. (1990). J. Organomet. Chem. 384, 41-47.

Pannell, K. H., Párkányi, L., Sharma, H. \& Cervantes-Lee, F. (1992). Inorg. Chem. 31, 522-524.

Párkányi, L. \& Henge, E. (1982). J. Organomet. Chem. 235, 273-276.

Párkányi, L., Hernandez, C. \& Pannell, K. H. (1986). J. Organomet. Chem. 301, 145-151.

Párkányi, L., Kálmán, A., Pannell, K. H., Cervantes-Lee, F. \& Kapoor, R. N. (1996). Inorg. Chem. 35, 6622-6624.

Párkányi, L., Kálmán, A., Sharma, S., Nolen, D. M. \& Pannell, K. H. (1994). Inorg. Chem. 33, 180-182.

Pienaar, E. W., Caira, M. R. \& Lötter, A. P. (1990a). J. Cryst. Spectrosc. Res. 23, 739-744.

Pienaar, E. W., Caira, M. R. \& Lötter, A. P. (1990b). J. Cryst. Spectr. Res. 23, 785-790.

Preut, H. \& Huber, F. (1976). Z. Anorg. Allg. Chem. 396, 92-96. 